\title{
Effect of lockdown during the novel coronavirus pandemic on diet and lifestyle of Indian children
}

\author{
*Sangeetha Shenoy ${ }^{1}$, Chandrika Rao ${ }^{1}$, Somashekar AR ${ }^{1}$
}

Sri Lanka Journal of Child Health, 2021; 50(3): 482-488

\begin{abstract}
Background: Although the coronavirus pandemic has spared children in terms of severity of disease, it has affected them in other ways by school closure and home confinement.
\end{abstract}

Objectives: To identify dietary and lifestyle changes during and after lockdown and their association with any sociodemographic factors.

Method: This was a cross sectional study with an online questionnaire which collected information on meals, vegetable intake, fruit intake, junk food intake and sugary drinks, hours of sleep during the day and night, screen time, time spent on outdoor, indoor, leisure activities and household chores before, during and after lockdown.

Results: Our study found a statistically significant increase in number of meals, vegetable and fruit intake, decrease in junk food intake, increase in daytime and night sleep, increase in screen time, decrease in outdoor physical activity and increase in time spent on indoor play, leisure activities and household chores. Change in sleep was more among older children and girls. Post lockdown, boys had an increase in outdoor physical activity and girls had an increase in screen time for educational purposes.

Conclusions: The lockdown implemented to contain the pandemic has had a negative effect on the dietary habits and lifestyle of children with a decrease in outdoor physical activity and increase in screen time contributing to an overall increase in sedentary behaviour. There was an increase in time spent on sleep especially in children more than 9 years of age.

\footnotetext{
${ }^{1}$ Ramaiah Medical College. Bangalore, India

*Correspondence: sangeethashenoy@yahoo.co.in$$
\text { iD }
$$$$
\text { https://orcid.org/ 0000-0001-5172-3776 }
$$

(Received on 15 March 2021: Accepted after revision on 23 April 2021)

The authors declare that there are no conflicts of interest

Personal funding was used for the project.

Open Access Article published under the Creative

Commons Attribution CC-BY (CC) (P)
DOI: https://dx.doi.org/10.4038/sljch.v50i3.0730

(Key words: adolescents, physical activity, screen time, sleep)

\section{Introduction}

Coronavirus pandemic has infected millions of people globally. Although the virus causes a milder disease and has a better prognosis in children ${ }^{1}$ compared to adults, the short and long term effects of the pandemic on children's physical and mental health are yet to be studied. Closure of schools and lockdown implemented by the government has brought about a major change in the routine of school-going children. The first phase of the nationwide lockdown was announced on $24^{\text {th }}$ March 2020 for 21 days till $18^{\text {th }}$ April. The lockdown was subsequently extended till $3^{\text {rd }}$ May. The third phase lasted till $17^{\text {th }}$ May and the fourth till $31^{\text {st }}$ May. From June 1, lockdown was lifted in a phased manner although it was still continued in containment zones. Malls, restaurants, and religious places were permitted to open from June 8 and cinema halls from October 15. Schools however have remained closed ever since and online classes were introduced since June 2020.

School environment provides children with a structured routine with respect to physical activity and meals, which in turn influences the sleep routine. Numerous studies ${ }^{2-4}$ concluded that children and adolescents gain more weight during summer holidays compared to regular school time. With schools closed for a prolonged period, physical activity and social interaction of children have been affected. Children have switched over to digital devices to fight boredom and interact with friends, thus increasing screen time, which in turn could affect sleep. Collateral adverse effects of the lockdown, implemented to contain the pandemic, need study. There are several studies examining effect of home confinement on dietary patterns and physical activity among adults ${ }^{5-7}$ and some s-10 $^{8-10}$ among children and adolescents. To the best of our knowledge there are no studies on the same in Indian children.

\section{Objectives}

To identify dietary and lifestyle changes during and after lockdown and their association with any sociodemographic factors. 


\begin{abstract}
Method
This was a cross sectional online survey. Questionnaire was uploaded on Google forms and the link shared via social media like whatsapp and email to personal contacts of the investigators, parent database of schools and patient database of the hospital. Parents of children in the age group 416 years were included in the study. Participants were also requested to forward the link to their friends and relatives to gather as much information from different parts of India and from different social strata. Survey questionnaire included questions on sociodemographic factors (gender, age, class, parental educational status and family income), adherence to lockdown, behaviour, in terms of staying at home or engaging in outdoor activities, dietary habits, screen time, sleep and physical activity of the child. Dietary component enquired about the number of meals, portions of vegetable intake, fruit intake, junk food intake and sugary drinks before, during and after lockdown. Physical activity part included questions on hours spent per day (for at least 5 days a week) on outdoor physical activity, indoor play, leisure activities and household chores before, during and after lockdown. Responses were saved at the end by pressing SUBMIT button. Content / face validity was carried out by giving questionnaire to experts and seeking their opinion. Reliability of questionnaire was checked prior to conduct of survey by a pilot study. Questionnaire was also translated into the local language and then back translated by 2 experts in the local language.
\end{abstract}

Sample size with justification: In the absence of published literature relating to the objectives of the study at the start of the survey, the findings from a study on H1N1 pandemic was considered for estimating the sample size. The study ${ }^{10}$ titled 'Effect of COVID-19 lockdown on lifestyle behaviours in children with obesity living in Verona, Italy: A longitudinal study' has revealed that $20.5 \%$ of the children went for physical activity as revealed by parents of children during the H1N1 pandemic which had a similar kind of school closure. Based on the above findings of the study, with a relative precision of $18 \%$, and a desired confidence level of $5 \%$, it was estimated that 460 children need to be recruited for the study.

Ethical issues: Ethical clearance was obtained from Institutional Ethics Committee of the Ramaiah Medical College, Bangalore, India (No. MSRMC/EC/AP-21/06-2020). The need for study was explained at the beginning of the questionnaire and informed written consent was taken from parents.
Statistical methods: All quantitative variables like age, time spent on various activities like sleep, screen time and physical activity are expressed as mean and standard deviation. Categorical variables such as gender are expressed as percentages. To test for differences in mean / median values before, during and after lockdown for the various quantitative variables, repeated measures of variance / Friedman test, as applicable, were employed. To test for pairwise comparison, Bon Ferroni test was used. Association between various factors was studied by the Chi square test of significance. $p<0.05$ was considered as statistically significant. Analysis was carried out using SPSS. Inc. released 2009.PASW statistics for Windows version 18.0. Chicago.

\section{Results}

There were 463 responses to questionnaire after excluding duplicate responses and responses from children below 4 and above 16 years. Of the responses, 233 were from parents of boys (mean age $10.27 \pm 3.187$ years) and 230 from parents of girls (mean age 10.67 \pm 2.947 years). Difference in mean ages was not statistically significant $(\mathrm{p}=0.2)$. Among boys, $35.2 \%, 35.6 \%$ and $29.2 \%$ and among girls $26.5 \%, 42.6 \%$ and $30.9 \%$ were in the $4-8$ year, $9-12$ year and 12-16 year age groups respectively. Demographic characteristics of children are shown in table 1 .

Table 1

Demographic characteristics of the children $(n=463)$

\begin{tabular}{|c|c|}
\hline Characteristic & n (\%) \\
\hline Age (years) & \\
\hline $4-8$ & $143(30.9)$ \\
\hline $9-12$ & $181(39.1)$ \\
\hline $13-15$ & $139(30.0)$ \\
\hline Gender: Males & $233(50.3)$ \\
\hline Type of house & \\
\hline Independent house & $222(47.9)$ \\
\hline Apartment & $242(52.1)$ \\
\hline Family Income (lakhs per annum) & \\
\hline$<5$ & $132(28.5)$ \\
\hline $5-<10$ & $51(11.0)$ \\
\hline $10-15$ & $32(06.9)$ \\
\hline$>15$ & $70(15.1)$ \\
\hline Did not answer & $178(38.4)$ \\
\hline Maternal educational status & \\
\hline Graduate / post graduate & $295(63.7)$ \\
\hline Post high school diploma & $74(16.0)$ \\
\hline Higher school certificate & $62(13.4)$ \\
\hline Primary and secondary school certificate & $32(07.0)$ \\
\hline Paternal educational status & \\
\hline Graduate / post graduate & $303(65.4)$ \\
\hline Post high school diploma & $63(13.6)$ \\
\hline Higher school certificate & $72(15.6)$ \\
\hline Primary and secondary school certificate & $25(05.4)$ \\
\hline
\end{tabular}

While $68 \%$ of children strictly did not leave the house during lockdown, $24 \%$ and $8 \%$ went out for 
essential and non-essential reasons respectively. Of the children who left the house during lockdown and early phase of opening of lockdown, $13 \%$ went for sports activity, $4.5 \%$ to places of worship, $1.1 \%$ for eating out, $9.3 \%$ for grocery shopping, $3.9 \%$ for outdoor play, $3.9 \%$ for hospital/doctor visit, $10.4 \%$ to relative's house and $6.9 \%$ to friend's house to play.

There was no significant change in the intake of sugary drinks. However, there was a statistically significant change in the number of meals, mean portions of vegetable, fruits and junk food intake before, during and after lockdown (Table 2). On further post hoc analysis, it was found that the change in number of meals per day was statistically significant when comparing before and during lockdown phase $(p=0.027)$. Similarly, change in vegetable and junk food intake was significant only between before and during lockdown group $(\mathrm{p}=0.000)$.

Table 2: Dietary and lifestyle changes of children before, during and after lockdown

\begin{tabular}{|l|c|c|c|c|}
\hline \multicolumn{1}{|c|}{ Variable } & $\begin{array}{c}\text { Before lockdown } \\
\text { Mean (SD) }\end{array}$ & $\begin{array}{c}\text { During lockdown } \\
\text { Mean (SD) }\end{array}$ & $\begin{array}{c}\text { After lockdown } \\
\text { Mean (SD) }\end{array}$ & p value \\
\hline Number of meals per day & $3.02(0.6)$ & $3.09(0.69)$ & $3.06(0.65)$ & 0.009 \\
\hline Vegetable intake (portions /day) $^{*}$ & $1.74(0.96)$ & $1.87(0.97)$ & $1.90(0.99)$ & 0.000 \\
\hline Junk food intake (number /day) & $0.85(0.83)$ & $0.7(0.89)$ & $0.78(0.88)$ & 0.000 \\
\hline Fruit intake (number/day) & $1.56(1.0)$ & $1.62(1.018)$ & $1.63(1)$ & 0.005 \\
\hline Drinks & $0.68(0.75)$ & $0.68(0.82)$ & $0.66(0.81)$ & 0.407 \\
\hline Day time sleep in hours/day (h/d) & $0.54(0.53)$ & $0.65(0.62)$ & $0.575(0.56)$ & 0.000 \\
\hline Night sleep in h/d* & $7.77(1.03)$ & $8.24(1.39)$ & $7.97(1.19)$ & 0.000 \\
\hline Educational screen time in h/d & $1.27(1.25)$ & $2.48(1.92)$ & $2.71(1.80)$ & 0.000 \\
\hline Recreational screen time in h/d & $1.46(1.08)$ & $2.55(1.62)$ & $2.11(1.4)$ & 0.000 \\
\hline Time spent on outdoor play in h/d & $1.03(0.92)$ & $0.482(0.82)$ & $0.743(0.91)$ & 0.000 \\
\hline Time spent on indoor play in h/d $/ \mathrm{d}^{*}$ & $0.66(0.61)$ & $1.26(0.98)$ & $0.959(0.79)$ & 0.000 \\
\hline Time spent on household chores in $\mathrm{h} / \mathrm{d}^{*}$ & $0.8(068)$ & $1.31(1.12)$ & $1.14(0.97)$ & 0.000 \\
\hline
\end{tabular}

*p value was calculated using non parametric test (Friedman)

There was a statistically significant increase in the hours spent on sleep during the day as well as at night during lockdown (Table 2). On further post hoc analysis, it was found that the time spent on sleep during the day increased significantly during the lockdown and decreased after the lockdown phase $(p=0.00)$. The difference in night sleep hours was significant between all 3 phases with the $p$ values being 0.00 in comparison of all phases of the lockdown. There was a statistically significant increase in screen time both for educational and recreational purposes during the lockdown phase (Table 2). On post hoc tests, this difference in screen time for educational purposes and recreational purposes was significant between all 3 phases of the lockdown $(\mathrm{p}=0.00)$.

There was a statistically significant decrease in time spent on outdoor play and a statistically significant increase in time spent on indoor play, leisure activities and household chores $(\mathrm{p}=0.00)$ (Table 2). On post hoc analysis, the difference was statistically significant between all the 3 groups $(p=0.00)$ for outdoor, indoor, leisure activities and household chores.

This change in eating habits and lifestyle of children was studied for an association with sociodemographic variables. On studying the influence of age on the eating habits, the decrease in junk food intake was seen in all 3 age groups but the difference was statistically significant only in the 912 year age group with a before lockdown mean of $0.851 \pm 0.73$ to $0.677 \pm 0.83$ with a $p$ value of 0.036 . With respect to napping and night sleep, there was an increase in time spent on sleep in all 3 age groups but the difference was statistically significant only above 9 years of age. With an increase in daytime sleep mean from $0.525 \pm 0.511$ to $0.707 \pm 0.60$ hours $(p=0.002)$ and $0.396 \pm 0.44$ to $0.536 \pm 0.58$ hours $(p=0.025)$ before and after lockdown in the 9-12 year age group and an increase in mean hours of night sleep from $7.75 \pm 0.89$ to $8.18 \pm 1.23$ hours $(\mathrm{p}=$ $0.00)$ and $7.75 \pm 1.17$ to $8.45 \pm 1.71$ hours $(p=0.00)$ in 9- 12 and 13-15 year age groups respectively. There was no influence of age on the screen time and physical activity outdoor and indoor as well as time spent on household chores.

With respect to gender, both boys and girls had a decrease in intake of junk food with a mean value of $0.839 \pm 0.76$ to $0.773 \pm 0.96(\mathrm{p}=0.412)$ and $0.867 \pm$ 0.89 to $0.626 \pm 0.80(\mathrm{p}=0.002)$ before and during lockdown amongst boys and girls respectively but the difference was statistically significant only in girls. Similarly, though the mean number of hours spent on daytime sleep increased from $0.517 \pm 0.52$ to $0.605 \pm 0.61(\mathrm{p}=0.097)$ in boys as compared to $0.561 \pm 0.54$ to $0.707 \pm 0.63(\mathrm{p}=0.008)$ in girls, the difference was statistically significant only in girls. However there was no effect of gender on night sleep, screen time or physical activity. On 
comparison of data between during and after lockdown, we found a statistically significant increase in time spent on physical activity among boys as compared to girls with an increase in mean value from $0.504 \pm 0.82$ to $0.878 \pm 0.97(\mathrm{p}=0.00)$ as compared to $0.459 \pm 0.82$ to $0.607 \pm 0.84$ (p $=0.058$ ). However, the increase in time spent in front of the screen for educational purposes increased significantly more in girls with a mean of $2.3 \pm 1.8$ to $2.66 \pm 1.74$ hours $(\mathrm{p}=0.034)$ as compared to 2.65 \pm 2.01 to $2.77 \pm 1.85)$ hours $(\mathrm{p}=0.504)$ in boys.

On comparison of the variables during the different phases of the pandemic, the family income, the type of house, family size, maternal and paternal educational status had no effect on the change in the lifestyle and diet of children.

\section{Discussion}

To the best of our knowledge this is the first study to examine the effects of lockdown on eating behaviour and lifestyle of Indian children. Our study had an equal representation of both genders and all age groups from 4 to 16 years and an almost equal representation of all socioeconomic levels. Our study found that $68 \%$ of children strictly adhered to lockdown rules and were confined to their homes. The rest went out for essential (24\%) and nonessential (8\%) reasons. The main reasons for going out were sports activity, grocery shopping and visit to relative's house. A retrospective survey in Japan during the $2009 \mathrm{H} 1 \mathrm{~N} 1$ pandemic found that $60 \%$ strictly stayed at home whereas the rest went out for essential and non-essential reasons ${ }^{11}$. Of the ones who went out, majority went out for shopping at the supermarket.

Our study found that the change in eating behaviour except for intake of sugary drinks was significant in terms of number of meals, fruit intake and vegetable intake. There was an increase in the number of meals and vegetable intake and a decrease in intake of junk food during the lockdown. This contrasted with an Italian study ${ }^{10}$ which tested the eating behaviour of obese children and found an increase in fruit, junk food and sugary drinks. The increase in vegetable intake and decrease in junk food could be because of children and parents both being at home and there being supervision of the child's diet which would not otherwise happen with working parents and school-going children.

American Academy of Sleep Medicine recommends 9-12 hours of sleep/day for 6-12 year old children and 8-10 hours of sleep/day for 13-18 year old adolescents for optimum health ${ }^{12}$. Our study found an increase in the hours spent on sleep both during day and night, similar to other studies ${ }^{10,13,14}$ which found an increase in the amount of time spent on sleep during the pandemic. The increase in sleep could be because there was no necessity for early waking as schools were closed. Even after onset of online classes, time spent on commuting to school is saved and children get to sleep longer. Another study ${ }^{15}$ however, found the pandemic to impact the quality of sleep in children due to a reduction in physical activity and increase in screen time with exposure to blue light.

Screen time is a major indicator of sedentary behaviour which has an impact on cognitive development, psychosocial health and adiposity in children ${ }^{16}$. Our study found a significant increase in the screen time of children, both for educational and recreational purposes, similar to other studies ${ }^{9,14}$. With school closure and restrictions in going out, children have resorted to digital devices during lockdown for entertainment and games as well as for extracurricular activities like dance, music and learning of musical instruments. This has continued in the post lockdown phase with most schools resorting to online classes to continue academic activities. Parents need to be counselled regarding time spent by children on mobile games, social media and television viewing.

A child's physical activity is closely related to school activities and participation in sports ${ }^{17}$. Canadian guidelines recommend 60 minutes of moderate to vigorous physical activity per day along with several hours of light physical activity for children. In addition, muscle and bone strengthening activities should be performed thrice a week ${ }^{18}$. Physical activity is needed not just for good cardiometabolic health and adiposity but also for bone health, motor skill development and emotional health ${ }^{19,20}$. Less than $10 \%$ school children met the above recommended guidelines on physical activity even prior to the pandemic ${ }^{21}$. Our study found a significant decrease in physical activity during lockdown similar to other studies ${ }^{9,14,22}$. Our study also found a significant increase in board games and traditional games. An interesting observation was an increase in time spent on household chores. A study in Canadian children also reported an increase in indoor activities like arts and craft, puzzles and games similar to our study ${ }^{14}$.

On studying the effect of sociodemographic variables on the above, children $<8$ years did not have a significant change in their diet and sleep time, whereas children 9-12 years had reduced their junk food intake during lockdown. Children $>9$ years had increased their sleep time. Another study found that older children had greater decrease in physical activity compared to younger children ${ }^{20}$. Our study concurs with another study which reported that 
younger children showed less change in their lifestyle in terms of sleep and $\operatorname{diet}^{14}$.

Girls had reduced intake of junk food and sleep more during the day compared to boys. During the post lockdown phase, increase in outdoor physical activity was significantly more in boys whereas the girls increased their screen time. This is similar to a study which found that girls spent more time on social media and sleep compared to boys during lockdown ${ }^{14}$. Although we did not find a difference in the lifestyle with respect to the house, staying in a detached house was associated with more physical activity according to one study ${ }^{14}$.

The main limitation of the study is the recall bias as the data were collected after the lockdown. The strength of the study is that it has compared all three phases of the pandemic and the fact that the study analyses other activities like indoor play and household chores. Further data could be collected from a larger sample. A qualitative study would also yield more information.

The observations of this study imply the need to have recommendations on physical activity, nutrition and screen time for children during the pandemic and also during school closures. With the virus still circulating among populations globally, lockdown being implemented in some parts of the world and school reopening being a matter of debate, there is an urgent need to bring about an awareness about these ill effects which could contribute to children getting pushed towards an unhealthy lifestyle, in turn contributing to obesity and media addiction.

\section{Conclusions}

The lockdown implemented to contain the pandemic has had a negative effect on the dietary habits and lifestyle of children with a decrease in outdoor physical activity and increase in screen time contributing to an overall increase in sedentary behaviour. There was an increase in time spent on sleep especially in children more than 9 years of age.

\section{References}

1. Ludvigsson JF. Systematic review of COVID-19 in children shows milder cases and a better prognosis than adults. Acta Paediatrica 2020; 109(6):1088-95.

https://doi.org/10.1111/apa.15270

PMid: 32202343 PMCid: PMC7228328

2. Rundle AG, Park Y, Herbstman JB, Kinsey EW, Wang YC. Covid -19 related school closings and risk of weight gain among children. Obesity (Silver Spring) 2020; 28(6): 1008-9.

https://doi.org/10.1002/oby.22813

PMid: 32227671 PMCid: PMC7440663

3. von Hippe PT, Powell B, Downey DB, Rowland NJ. The effect of school on over weight in childhood: Gain in body mass during the school year and during summer vacation. American Journal of Public Health 2007; 97(4): 696-702. https://doi.org/10.2105/AJPH.2005.08075 4

PMid: 17329660 PMCid: PMC1829359

4. Wang YC, Vine S, Hsiao A, Rundle A, Goldsmith J. Weight related behaviours when children are in school versus on summer breaks: Does income matter? Journal of School Health 2015; 85(7): 45866.

https://doi.org/10.1111/josh.12274

PMid: 26032276

5. Górnicka M, Drywień ME, Zielinska MA, Hamułka J. Dietary and lifestyle changes during COVID-19 and the subsequent lockdowns among Polish adults: A crosssectional online survey PLifeCOVID-19 study. Nutrients 2020; 12(8): 2324. https://doi.org/10.3390/nu12082324 PMid: 32756458 PMCid: PMC7468840

6. Ammar A, Brach M, Trabelsi K, Chtourou $\mathrm{H}$, Boukhris O, Masmoudi L, et al. Effects of COVID-19 home confinement on eating behaviour and physical activity: Results of the ECLB-COVID19 International Online Survey. Nutrients 2020; 12(6): 1583. https://doi.org/10.3390/nu12061583 PMid: 32481594 PMCid: PMC7352706

7. Di Renzo L, Gualtieri P, Pivari F, Soldati L, Attinà $\mathrm{A}$, Cinelli $\mathrm{G}$, et al. Eating habits and lifestyle changes during COVID-19 lockdown: an Italian survey. Journal of Translational Medicine 2020; 18(1): 1-5. https://doi.org/10.1186/s12967-02002399-5

PMid: 32513197 PMCid: PMC7278251

8. Schmidt SC, Anedda B, Burchartz A, Eichsteller A, Kolb S, Nigg C, et al. Physical activity and screen time of children and adolescents before and during the COVID-19 lockdown in Germany: a 
natural experiment. Scientific Reports 2020; 10(1): 1-2.

https://doi.org/10.1038/s41598-020-

78438-4

PMid: 33311526 PMCid: PMC7733438

9. Xiang M, Zhang Z, Kuwahara K. Impact of COVID-19 pandemic on children and adolescents' lifestyle behaviour larger than expected. Progress in Cardiovascular Diseases 2020; 63(4): 531-2.

https://doi.org/10.1016/j.pcad.2020.04.013

PMid: 32360513 PMCid: PMC7190470

10. Pietrobelli A, Pecoraro L, Ferruzzi A et al. Effect of COVID-19 lockdown on lifestyle behaviours in children with obesity living in Verona, Italy: A Longitudinal study. Obesity (Silver Spring) 2020; 28(8): 13826.

https://doi.org/10.1002/oby.22861

PMid: 32352652 PMCid: PMC7267384

11. Mizumoto K, Yamamoto T, Nishiura H. Contact behaviour of children and parental employment behaviour during school closures against the pandemic influenza A (H1N1-2009) in Japan. Journal of International Medical Research 2013; 41(3): 716-24.

https://doi.org/10.1177/030006051347806 1

PMid: 23613502

12. Paruthi S, Brooks LJ, D'Ambrosio C, Hall WA, Kotagal S, Lloyd RM, et al. Consensus statement of the American Academy of Sleep Medicine on the recommended amount of sleep for healthy children: methodology and discussion. Journal of Clinical Sleep Medicine 2016; 12(11): 1549-61. https://doi.org/10.5664/jcsm.6288

PMid: 27707447 PMCid: PMC5078711

13. Wright KP, Linton SK, Withrow D, Casiraghi L, Lanza SM, de la Iglesia H, et al. Sleep in university students prior to and during COVID-19 stay-at-home orders. Current Biology 2020; 30(14): R797R798.

https://doi.org/10.1016/j.cub.2020.06.022

PMid: 32693068 PMCid: PMC7284257

14. Moore SA, Faulkner G, Rhodes RE, Brussoni M, Chulak-Bozzer T, Ferguson
LJ, et al. Impact of the COVID-19 virus outbreak on movement and play behaviours of Canadian children and youth: a national survey. International Journal of Behavioral Nutrition and Physical Activity 2020; 17(1): 1-1. https://doi.org/10.1186/s12966-02000987-8

PMid: 32631350 PMCid: PMC7336091

15. Dellagiulia A, Lionetti F, Fasolo $M$, Verderame C, Sperati A, Alessandri G. Early impact of COVID-19 lockdown on children's sleep: a 4-week longitudinal study. Journal of Clinical Sleep Medicine 2020; 16(9): 1639-40.

https://doi.org/10.5664/jcsm. 8648

PMid: 32620188

16. LeBlanc AG, Spence JC, Carson V, Connor Gorber S, Dillman C, Janssen I, et al. Systematic review of sedentary behaviour and health indicators in the early years (aged 0-4 years). Applied Physiology, Nutrition, and Metabolism 2012; 37(4): 753-72.

https://doi.org/10.1139/h2012-063

PMid: 22765839

17. Hoffmann B, Kobel S, Wartha O, Kettner S, Dreyhaupt J, Steinacker JM. High sedentary time in children is not only due to screen media use: a cross-sectional study. BMC Pediatrics 2019; 19(1): 154. https://doi.org/10.1186/s12887-019-15218

PMid: 31096946 PMCid: PMC6521402

18. Tremblay MS, Carson V, Chaput J-P, Connor Gorber S, Dinh T, Duggan M, et al. Canadian 24-hour movement guidelines for children and youth: An integration of physical activity, sedentary behaviour, and sleep. Applied Physiology, Nutrition and Metabolism 2016; 41: S311-S327. https://doi.org/10.1139/apnm-2016-0151 PMid: 27306437

19. Janssen I, LeBlanc AG. Systematic review of the health benefits of physical activity and fitness in school-aged children and youth. International Journal of Behavioral Nutrition and Physical Activity 2010; 7: 40. https://doi.org/10.1186/1479-5868-7-40 PMid: 20459784 PMCid: PMC2885312 
20. Saunders TJ, Gray CE, Poitras VJ, Chaput JP, Janssen I, Katzmarzyk PT, et al. Combinations of physical activity, sedentary behaviour and sleep: Relationships with health indicators in school-aged children and youth. Applied Physiology, Nutrition and Metabolism 2016; 41: S283-S293.

https://doi.org/10.1139/apnm-2015-0626

PMid: 27306434

21. Bates LC, Zieff G, Stanford K, Moore JB, Kerr ZY, Hanson ED, et al. COVID-19 impact on behaviours across the 24-hour day in children and adolescents: physical activity, sedentary behavior, and sleep. Children 2020; 7(9): 138.

https://doi.org/10.3390/children7090138

PMid: 32947805 PMCid: PMC7552759

22. Dunton G, Do B, Wang S. Early effects of the COVID-19 pandemic on physical activity and sedentary behaviour in US Children. BMC Public Health 2020; 20(1): 1351.

https://doi.org/10.1186/s12889-020-

09429-3

PMid: 32887592 PMCid: PMC7472405 